\title{
1 Comparison of four light use efficiency models for estimating 2 terrestrial gross primary production
}

3 Liang-Xia Zhang ${ }^{\mathrm{a}, \mathrm{b}}$, De-Cheng Zhou ${ }^{\mathrm{a}}$, Jiang-Wen Fan ${ }^{\mathrm{b}}$, Zhong-Min Hu ${ }^{\mathrm{b} \text {, * }}$

4 a Jiangsu Key Laboratory of Agricultural Meteorology, and College of Applied

5 Meteorology, Nanjing University of Information Science and Technology, Nanjing

6210044 , China

$7 \quad$ b Institute of Geographic Sciences and Natural Resources Research, Chinese Academy

8 of Sciences, Beijing 100101, China

$9 \quad *$ Correspondence to: Zhongmin Hu (huzm@igsnrr.ac.cn)

10 Key words: Gross primary productivity, Remote sensing, MODIS, EVI, FluxNet,

11 Eddy covariance 


\section{Abstract:}

Light use efficiency (LUE) models that with different structures (i.e., methods to address environmental stresses on LUE) have been widely used to estimate terrestrial gross primary production (GPP) because of their theoretical soundness and practical conveniences. However, a systematic validation of those models with field observations across diverse ecosystems is still lacking and whether the model can be further improved by structural optimization remains unclear. Using GPP estimates at global 51 eddy covariance flux towers that cover a wide climate range and diverse vegetation types, we evaluated the performances of the four major LUE models (i.e., Carnegie-Ames-Stanford approach (CASA), Global Production Efficiency Model (GLO-PEM), Vegetation Photosynthesis Model (VPM), and Eddy Covariance-Light Use Efficiency (EC-LUE)) and examined the possible further improvement of the better-performed model(s) via model structural optimization. Our results showed that the GLO-PEM, VPM, and EC-LUE exhibited the similar capabilities in simulating GPP (explained around $68 \%$ of the total variations) and overall performed better than CASA (58\%). Nevertheless, the EC-LUE and VPM were the optimal ones because they required less model inputs than the GLO-PEM. For the two optimal models, we found that the minimum method is better than the multiplication approach to integrate multiple environmental stresses on LUE. Moreover, we found that the VPM can be further improved by incorporating the constraint of water vapor deficit $\left(\mathrm{VPD}_{\mathrm{s}}\right)$. We suggested that a modified VPM by using minimum method and adding $\mathrm{VPD}_{\mathrm{s}}$ may be the best model in estimating large-scale GPP if high-quality remote sensing data 
34 available, otherwise, the modified models with the water stress reflected by VPD

35 only is optimal.

36 


\section{Introduction}

Gross Primary Production (GPP), the sum of photosynthetic carbon uptake by vegetation, is a critical indicator of ecosystem carbon cycle (Field et al., 1995; Goetz et al., 1999; Chapin et al., 2002). Because GPP cannot be directly observed at the regional or global scale, models have emerged as the major approaches for predicting terrestrial ecosystem GPP over large areas recently (Canadell et al., 2000). Among these, the light use efficiency (LUE) models have been widely used because of its theoretical soundness and practical convenience (Running et al., 2000).

The LUE models were usually developed based on two basic assumptions (Running et al., 2004): (a) the ecosystem GPP related directly to absorbed photosynthetically active radiation (APAR) through LUE, and (b) the actual LUE is lower than the potential value because of environmental stresses (e.g., low and high temperature and drought) (Landsberg, 1986). The GPP function of them takes the form of $G P P=P A R \times f P A R \times \varepsilon_{\max } \times f$. Therein, $P A R$ is the incident photosynthetically active radiation $\left(\mathrm{M} \mathrm{J} \mathrm{m}^{-2}\right)$ per day or month, $f P A R$ is the fraction of $P A R$ absorbed by the vegetation canopy, $\varepsilon_{\max }$ is the potential LUE $\left(\mathrm{g} \mathrm{C} \mathrm{m}^{-2} \mathrm{MJ}^{-1} \mathrm{APAR}\right)$ without environment stress, and $f$ is a scalar varying from 0 to 1 that represents the reduction of LUE relative to $\varepsilon_{\max }$ due to environmental stresses (e.g., air temperature stress and water availability). The $\varepsilon_{\max } \times f$ indicates the actual LUE. Note that the actual LUE can be also defined as the function of Photochemical Reflectance Index (PRI) (Drolet et al., 2005, 2008), which is out the scope of this study. 
In practice, several LUE models, such as Carnegie-Ames-Stanford approach (CASA, Potter et al., 1993), Global Production Efficiency Model (GLO-PEM, Prince and Goward, 1995; Goetz et al., 1999), Moderate Resolution Imaging Spectroradiometer (MODIS) GPP algorithm (Running et al., 1999, 2000), Vegetation Photosynthesis Model (VPM, Xiao et al., 2004a, b), and Eddy Covariance-Light Use Efficiency (EC-LUE, Yuan et al., 2007), had been developed using different $f$ scalars. Specifically, there were two major differences in the structure of $f$ across LUE models. First, the strategies to integrate multiple environmental stresses into $f$ were different. Models such as GLO-PEM, CASA, and VPM (Potter et al., 1993; Prince and Goward, 1995; Xiao et al., 2004a) used the multiplicative method, while the EC-LUE (Yuan et al., 2010) utilized the minimum method based on the theory of Liebig's law. Second, the water stress scalar $(f w)$, a key environmental constraint on the LUE, was quantified in different ways. It had been estimated by the water stress in the soil and (or) in the air (e.g., atmosphere water vapor deficit) in some models (e.g., GLO-PEM and CASA), and via land water index that can reflect the vegetation water stress in the other models (e.g., VPM and EC-LUE). For instance, $f w$ was calculated by the evaporative fraction in the EC-LUE model (Yuan et al., 2007), which was considerate to be a good indicator of moisture conditions (Kurc and Small, 2004). However, the performances of those models are rarely validated with field observations across large areas (e.g., Yuan et al., 2010), and little is known about whether the better-performed LUE models can be further improved by model structural optimization (Medlyn, et al., 2011; Hashimoto et al., 2012; Yang et al., 2013). Specifically, most previous efforts 
focused on only one of the LUE models and compared the model with other kinds of models at quite a few flux sites (Zhang et al., 2007; Coops et al., 2009; Wu et al., 2010). Yuan et al. (2014) might be the first to compare multiple LUE models via field observations over large areas, but they did not investigate the strength and weakness of the various model structures, as a result, the potential of model improvement by structural optimization.

$$
\text { models (i.e., CASA, GLO-PEM, VPM, and EC-LUE) by in-situ GPP estimates at } 51
$$

global eddy covariance (EC) flux towers via using model-independent parameter values. Our objectives were to (1) identify the better-performed model(s) in estimating GPP over large areas and (2) investigate the optimal model structure, including the strategy to integrate multiple environmental stresses (i.e., multiplication or minimum) and the method to address water stress, for the further improvement of the LUE models. The performance of the well-known LUE-based MODIS-GPP algorithm was not assessed because the daily minimum temperature, an important parameter for the model, was not available in this study. However, the water stress expression used by it was evaluated when we discussed the optimal model structure.

\section{Materials and Methods}

\subsection{Model Overview}

\subsubsection{The CASA model}


101 estimate monthly GPP and NPP with satellite data, monthly temperature and

102 precipitation, and soil properties. The actual LUE $\left(\varepsilon_{\mathrm{g}}, \mathrm{g} \mathrm{C} \mathrm{m}^{-2} \mathrm{MJ}^{-1} \mathrm{APAR}\right)$ in the

103 model is defined as follows:

$104 \varepsilon_{g}=\varepsilon_{\max } \times f t 1 \times f t 2 \times f w$

$105 f t 1=1.1814\left(1+e^{\left(0.3\left(-T_{\mathrm{opt}}-10+T\right)\right)}\right) /\left(1+e^{\left(0.2\left(T_{\mathrm{opt}}-10-T\right)\right)}\right)$

106

$$
f t 2=0.8+0.02 T_{\mathrm{opt}}-0.0005 T_{\mathrm{opt}}^{2}
$$

108 where $\varepsilon_{\max }$ is the potential LUE ( $\mathrm{g} \mathrm{C} \mathrm{m}^{-2} \mathrm{MJ}^{-1}$ APAR), $f t 1$ represents the effects of

109 very high and very low temperatures on $\varepsilon_{\max }, f t 2$ indicates the effects of the

110 temperature above or below the optimum temperature $\left(T_{\text {opt }}\right)$ on $\varepsilon_{\max }$, and $f w$

111 represented by soil moisture condition $\left(W_{s}\right)$ illustrates the water stress on $\varepsilon_{\max }$. EET

112 and PET are the estimated and potential evapotranspiration, respectively.

114 follows:

$115 E E T=\min (P P T+(P E T-P P T) R D R,(P P T+(S M-W P T)))$, when $P P T<P E T(2.1 \mathrm{e})$

$117 \quad R D R=(1+a)\left(1+a S M^{b}\right)$

118 where $R D R$ is the relatively drying rate scalar for potential water extraction, $S M$ is the

119 soil moisture (volumetric moisture content, $\mathrm{m} / \mathrm{m}$ ), WPT, $a$, and $b$ are the 
121 Soil moisture is estimated using a one-layer bucket model (Malmstrom et al.,

122 1997):

$123 S M_{t}=S M_{t-1}-\left(P E T_{t}-P P T_{t}\right) R D R_{t-1}$, for $P P T<P E T$

124

$$
S M_{t}=S M_{t-1}-\left(P P T_{t}-P E T_{t}\right), \text { for } P P T \geq P E T
$$

125 where $S M_{t}$ and $S M_{t-1}$ are the soil moisture at the $8 t$ and $8(t-1)$ days, respectively, in

126 order to keep accordance with the temporal resolution of MODIS products that being

127 used by us.

\subsubsection{The GLO-PEM model}

131 Goward (1995) is driven by the variables derived almost entirely from satellite

132 products. GLO-PEM has been successfully utilized to estimate global terrestrial GPP

133 and NPP (Prince and Goward, 1995; Cao et al., 2004). The $\varepsilon_{g}$ in the model is

134 calculated as follows:

$135 \varepsilon_{g}=\varepsilon_{\max } \times f t \times f w$

$136 f w=W_{s} \times V P D_{s}$

137 where $f t$ represents the effects of temperature on $\varepsilon_{\max }$, and $f w$ is reflected by soil

138 moisture condition $\left(W_{s}\right)$ and atmosphere moisture condition $\left(V P D_{s}\right)$. 
$139 f t=\frac{\left(T-T_{\min }\right)\left(T-T_{\max }\right)}{\left[\left(T-T_{\min }\right)\left(T-T_{\max }\right)\right]-\left(T-T_{\text {opt }}\right)^{2}}$

$141 \quad \delta_{q}=Q w(T)-q$

142 where $T_{\min }$ and $T_{\max }$ are the minimum and maximum temperature for photosynthetic

143 activities, respectively, $\delta_{q}$ is the specific humidity deficit $\left(\mathrm{g} \mathrm{kg}^{-1}\right), Q w(T)$ is the

144 saturated specific humidity at the air temperature, and $q$ is the specific air humidity. $f t$

145 was set to be zero if the air temperature was lower than $T_{\min }$. Since the calculation of

$146 W_{s}$ in the original GLO-PEM needs the variable of equilibrium evapotranspiration,

147 and the accuracy of which is poor at local scale (Jarvis \& MacNaughton, 1986;

148 Prentice et al., 1992, 1993; Cao et al., 2004), we thus adopted the $W_{s}$ function in

149 CASA (Eq. (2.1d)) for GLO-PEM in this study.

\subsubsection{The VPM model} chloroplast) and non-photosynthetic vegetation (mostly senescent foliage, branches, and stems). The VPM has been successfully used to simulate GPP in different ecosystems, including tropical evergreen forest (Xiao et al., 2005b), temperate 
estimated as follows:

$161 f w=W I=\frac{1+L S W I}{1+L W S \mathrm{I}_{\max }} \times P_{s}$

162 where $f t$ is the same as that in GLO-PEM (Eq. (2.2b)), and $f w$ is reflected by land

163 water index $(W I)$ that was calculated by satellite-derived land surface water index

164 (LSWI) (Xiao et al., 2002; Boles et al., 2004) with consideration of the phenology

165 effect on $\varepsilon_{\max }\left(P_{s}\right)$ (Xiao et al., 2005b).

The $P_{s}$ in the model is calculated as follow:

$167 P_{s}=\frac{1+L S W I}{2}$ (before leaf full expansion) or 1 (after leaf full expansion)

168 where $L S W I_{\max }$ is the maximum $L S W I$ within the plant growing season. In this study,

169 we took the maximum $L S W I$ value within the photosynthetically active period as the

$170 L S W I_{\max }$ when multi-year $L S W I$ data are available and assumed that $P_{S}$ equaled to 1

171 for evergreen forests (Xiao et al., 2004a). LSWI is calculated via the NIR (841-875

$172 \mathrm{~nm})$ and SWIR (1628-1652 nm) bands of MODIS images as follow:

$173 \quad L S W I=\frac{\rho_{\text {nir }}-\rho_{\text {swir }}}{\rho_{\text {nir }}+\rho_{\text {swir }}}$

\subsubsection{The EC-LUE model}

177 assumes that the LUE is controlled by air temperature or ecosystem water stress, 
178 whichever is most limiting. The EC-LUE has been successfully used to estimate the

179 GPP in forest, grassland, savanna, cropland, and the global GPP (Yuan et al., 2007;

180 Yuan et al., 2010). The $\varepsilon_{g}$ in which is estimated as:

$181 \varepsilon_{g}=\varepsilon_{\max } \times \min (f t, f w)$

$182 f w=W I=E F=\frac{L E}{L E+H}$

183 where $f t$ is the same as that in GLO-PEM (Eq. (2.2b)), and $f w$ represented by $W I$ is

184 expressed by evaporative fraction (EF) and can be calculated by the EC-measured

185 latent heat flux (LE) and sensible heat flux $(\mathrm{H})\left(\mathrm{W} \mathrm{m}^{-2}\right)$. Unlike the VPM, GLO-PEM,

186 and CASA models that assume the impacts of multiple environmental stresses on $\varepsilon_{\max }$

187 are multiplicative, the EC-LUE hypothesizes that the influences of temperature and

188 water stress follow the Liebig's law of minimum.

\subsection{Data}

We used the in-situ observations at 51 global EC flux sites in the Fluxnet (ORNL

DAAC, 2012) to assess the performances of the above-mentioned four models (Table

193 1). These sites cover a wide climate range and diverse plant functional types,

194 including savanna (4 sites), grassland (7 sites), cropland (7 sites), shrubland (2 sites),

195 mixed forest (MF, 4 sites), deciduous broadleaf forest (DBF, 7 sites), evergreen

196 broadleaf forest (EBF, 2 sites), and evergreen needleleaf forest (ENF, 18 sites). For

197 each site, EC flux data were extracted from the Level 4 product (download from

198 http://fluxnet.ornl.gov/). In the dataset, the half-hourly GPP were calculated by the net 
ecosystem exchange and ecosystem respiration. The data gaps associated with equipment failures and unsuitable micrometeorological conditions were filled using the Artificial Neural Network method (Papale and Valentini, 2003) and/or the Marginal Distribution Sampling method (Reichstein et al., 2005). The half-hourly GPP was summed to obtain daily GPP and then averaged to 8-day interval in order to keep accordance with the temporal resolution of MODIS data.

Two MODIS products including enhanced vegetation index (EVI) and surface reflectance data (i.e., NIR (841-875 nm) and SWIR (1628-1652 nm) bands) were used in this study. These data were provided by the Oak Ridge National Laboratory's Distributed Active Archive Center (DAAC) (ORNL DAAC, 2012). EVI time series (16-day composites with a spatial resolution of $250 \mathrm{~m}$ ) were obtained from the MODIS Vegetation Indices products (MOD13Q1), and the NIR and SWIR bands data (8-day composites with a spatial resolution of 500m) were acquired from the MODIS Surface Reflectance products (MOD09A1). Based on the geo-location information (latitude and longitude) of the 51 global EC flux sites, all data were extracted from 1.5 $\mathrm{km} \times 1.5 \mathrm{~km}$ area centered on the flux tower (Wu et al., 2010). Because there always remains some biases of EVI caused by cloud-contamination or other noises (Hill et al., 2006), these data were further smoothed over seasons by asymmetric Gaussian method which was proposed to be effective in obtaining high-quality NDVI/EVI time-series (Jönssonb and Eklundha, 2004).

The half-hourly meteorological observations (e.g., PAR, air temperature, precipitation, and relative humidity) (Level 4 product) were downloaded from the 
221 Fluxnet website (ORNL DAAC, 2012) as well. The meteorological measurements were up-scaled to daily level and then to 8-day interval. Soil attributes were acquired from the global soil properties map provided by the FAO (http://www.fao.org).

\subsection{Analysis}

As the major focus of this paper was to examine the impacts of model structure, rather than the parameters, on modelling accuracies, we used a universal set of parameters for all the models and all the vegetation types in this study. The expression of $f P A R$ was adopted from VPM (i.e., $f P A R=\mathrm{EVI}$ (Xiao et al., 2005a)), $\varepsilon_{\max }$ was set to $2.25 \mathrm{~g} \mathrm{C} \mathrm{m}^{-2} \mathrm{MJ}^{-1}$ APAR (Yuan et al., 2010), $T_{\min }, T_{\mathrm{opt}}$, and $T_{\max }$ were set to 0,25 , and $40^{\circ} \mathrm{C}$, respectively (Kotchenova et al., 2004; Xiao et al., 2004a). Then we conducted the analysis in following steps:

1) We identified the better-performed LUE model(s) by comparing the model accuracies of the four models at all the 51 EC sites.

2) We explored the optimal method to integrate environmental stresses into scalar $f$ by comparing the performances of the better model(s) that being found in above step under the two different integration methods (i.e., multiplication and minimum).

3) We assessed the performances of the optimal LUE model(s) when the water stress was represented by land water stress index (WI) only, air moisture stress $\left(\mathrm{VPD}_{\mathrm{s}}\right)$ only, or both to investigate the optimal method to define water stress. The methods to characterize VPD , included that of the GLO-PEM (Cao et al., 2004, Eq (2.2d)), 


$$
M O D_{-} V P D_{s}=\frac{V P D_{\max }-V P D}{V P D_{\max }-V P D_{\min }}
$$

245 where $V P D_{\max }$ is the daylight average vapor pressure deficit when the actual LUE $\left(\varepsilon_{g}\right)$ 246 equalled to the potential value $\left(\varepsilon_{\max }\right), V P D_{\min }$ is the daylight average vapor pressure

247 deficit when $\varepsilon_{g}=0 . V P D_{\max }$ and $V P D_{\min }$ for each vegetation type were derived from

248 Biome Parameter Look-Up Table (BPLUT) for MOD17 (Heinsch et al., 2003).

$249 S W H_{-} V P D_{s}=\frac{V P D_{\max }-V P D}{V P D_{\max }}(V P D>0.5 \mathrm{kPa})$ or $1(\mathrm{VPD} \leq 0.5 \mathrm{kPa})$

250 where $V P D_{\max }$ is $3 \mathrm{kPa}$.

253 (The MathWorks, Inc). A higher $R^{2}$, lower RMSE and BIAS are believed to have a

254 better model performance. The RMSE and BIAS are calculated as follows:

$255 \quad R M S E=\sqrt{\frac{\sum\left(O_{i}-M_{i}\right)^{2}}{N}}$

$256 \quad B I A S=\frac{\sum\left(M_{i}-O_{i}\right)}{N}$

257 where $O_{\mathrm{i}}$ and $M_{\mathrm{i}}$ represent the estimated and modeled GPP, respectively, and $N$ 258 indicates the total number of estimates at the study site. 


\section{Results and Discussion}

261

262

263

264

265

266

267

268

269

270

271

272

273

274

275

276

277

278

279

280

\subsection{Comparisons of the four LUE models in estimating GPP}

Overall, the EC-LUE, GLO-PEM, and VPM explained the similar amounts of the GPP's variations, characterized by the $R^{2}$ of $0.69,0.69$, and 0.68 , respectively, and performed better than the CASA model (0.58) (Table 2). Although the $R^{2}$ for the EC-LUE, GLO-PEM, and VPM were similar, the RMSE for GLO-PEM (2.06 $\mathrm{g} \mathrm{C} \mathrm{m}^{-2}$ day $\left.^{-1}\right)$ was lower than that for the VPM $\left(2.45 \mathrm{~g} \mathrm{C} \mathrm{m}^{-2}\right.$ day $\left.^{-1}\right)$ and EC-LUE $\left(2.41 \mathrm{~g} \mathrm{C}^{-}\right.$ $\mathrm{m}^{-2}$ day $\left.^{-1}\right)$. Notably, all the four models underestimated the ecosystem GPP, with the least bias in the CASA model (i.e., $-0.43 \mathrm{~g} \mathrm{C} \mathrm{m}^{-2}$ day $^{-1}$ ).

In addition, the model performances varied greatly across vegetation types (Figs. 1-2). At the non-forest sites (i.e., savanna, grassland, cropland, and shrubland), the mean $R^{2}$ for EC-LUE (i.e., 0.67) was higher than that for VPM, GLO-PEM, and CASA by $7.11 \%, 8.07 \%$, and $36.79 \%$, respectively. However, at the forest sites (i.e., MF, DBF, EBF and ENF), the mean $R^{2}$ for VPM and GLO-PEM were the same (i.e., 0.72), and higher than that for EC-LUE and CASA by $3.57 \%$ and $12.90 \%$, respectively. Moreover, the VPM had the largest $R^{2}$ in DBF while the GLO-PEM had the greatest $R^{2}$ in MF, EBF, and ENF. CASA exhibited the poorest accuracy in all the vegetation types than the other three models.

The higher accuracies of EC-LUE, GLO-PEM, and VPM than CASA indicated that all these three models might be robust in estimating ecosystem GPP over large areas. However, it would be better if with briefer model structure and fewer input 
variables without sacrificing of model accuracy (Goetz et al., 1999; Yang et al., 2013).

Among those three models, the water stress expression (i.e., $f w$ ) in GLO-PEM (Eq. (2.1d)) was more complicated than the other two models (EC-LUE and VPM).

Specifically, the $f w$ for GLO-PEM needs soil moisture information which required more input variables including climate data (e.g., precipitation) and soil properties (e.g., soil texture) than the other two models. In contrast, the calculation of $f w$ for EC-LUE and VPM was much simple and the required data (e.g., MODIS surface reflectance products) was easy to obtain. Therefore, considering both the model performance and input variables, VPM and EC-LUE were the optimal LUE models for simulating GPP over large areas.

The better performances of EC-LUE and VPM compared to CASA in all the vegetation types may be due to the more reasonable expression of $f w$ and/or temperature stress (i.e., $f t$ ) in the two models than CASA. First, the CASA assumes little water stress on the GPP's variability (Potter et al., 1993), and used the value of 0.5 to 1 for $f w$. However, the value of $f w$ estimated by us was much less than 0.5 at the water-limited non-forest sites (e.g., grassland, shrubland, and savanna). For example, the average values of $f w$ in EC-LUE and VPM were 0.24 and 0.39 at the non-forest sites, respectively. These suggested that the $f w$ of CASA might be not enough to reflect the drought stress on the GPP in non-forest sites. This can be further exemplified by the increased $R^{2}$ and decreased RMSE for CASA at the non-forest sites when we used $f w$ of EC-LUE and VPM (Eq. (2.4b) and (2.3b)) in the model $\left(R^{2}\right.$ increased by $19.41 \%$ vs. $1.90 \%$, and RMSE decreased by $51.30 \%$ vs. $54.83 \%$ ). 
Second, the CASA used the optimal temperature only to represent the $f t$, while the VPM and EC-LUE utilized the minimum, maximum, and optimal temperature to reflect the effects of the $f t$ on the vegetation production. Our results demonstrated that the modeling accuracy of CASA improved significantly after using the similar $f t$ (Eq. (2.2c)) of the VPM and EC-LUE at all the sites. Specifically, the mean $R^{2}$ at the non-forest sites and forest sites increased by $8.91 \%$ and $10.09 \%$, respectively. Notably, the expression of environmental stresses in the modified CASA (with $f t$ of the VPM and EC-LUE) was just short of the $\operatorname{VPD}_{\mathrm{s}}$ (Eq. (2.2d)) compared to GLO-PEM (Eq. (2.2a)), but the mean $R^{2}(0.64)$ of the modified CASA in all the vegetation types was $7.81 \%$ lower than that of GLO-PEM (0.69), suggesting that the performances of the two optimal LUE models (VPM and EC-LUE) might be further improved by adding $\mathrm{VPD}_{\mathrm{s}}$, and we will discuss this in section 3.3.

The varying performances of the EC-LUE, GLO-PEM, and VPM across vegetation types can be mainly attributed to the different water stress scalars $(f w)$ used by them. Specifically, the EC-LUE performed best (compared to the GLO-PEM and VPM) in the non-forest sites (e.g., savanna and grassland that usually have semi-arid climates), since the $f w$ used by it (evaporative fraction, EF) related closely to the surface soil water content, which was documented as the major water stress on plant growth in those kinds of ecosystems (Sala et al., 1988; Kurc and Small, 2004). By contrast, the GLO-PEM and VPM performed better in the forest sites (characterized by the high annual precipitation and the deep roots system for accessing deep soil water in dry seasons), since the $f w$ utilized by them (soil water condition $\left(W_{\mathrm{s}}\right)$ and 
atmosphere moisture condition $\left(\mathrm{VPD}_{\mathrm{s}}\right)$, and the land surface water index (LSWI), respectively) can reflect both the leaf and canopy water content, which were believed to mainly limit the light use efficiency of plants in those ecosystems (Nepstad et al., 1994; Xiao et al., 2005b). Moreover, the VPM had better performance than GLO-PEM in DBF because the $f w$ in it included the phenology scalar $\left(P_{\mathrm{s}}\right)$, which can account for the effects of leaf age on photosynthesis (Xiao et al., 2004b). Many studies suggested that the development of new leaves and senescence of old leaves (i.e., phenology) impacted the photosynthetic capacity significantly in DBF (Wilson et al., 2001; Barr et al. 2007, Richardson et al. 2007). Comparatively, the GLO-PEM showed higher modelling accuracy in MF, EBF, and ENF compared to the VPM, possibly due to the consideration of air water stress (i.e., $V_{P D}$ ) in the $f w$ of the model (Cao et al., 2004). It was well-known that the stomata would progressively close to protect the leaf from desiccation as the air dries, which could decrease the photosynthetic capacity (Jarvis, 1976). The LSWI used in the VPM cannot reflect the air water condition because of the weak effects of atmospheric water vapor on NIR (841-875 nm) and SWIR (1628-1652 nm) bands that were used to calculate LSWI (Gao et al., 1996). These together highlight the possible further improvement of the LUE models by optimizing $f w$ scalar.

\subsection{Comparisons of the methods to integrate multiple environmental stresses}

For the two optimal LUE models (i.e., EC-LUE and VPM), the methods to 
integrate environmental stresses were totally different (i.e., multiplication for VPM

347 and minimum based on Liebig's law for EC-LUE). We thus exchanged their methods

348 to check which method was better. Results indicated that the $R^{2}$ for the modified

349 EC-LUE decreased by $4.82 \%$, with an $11.03 \%$ increase in RMSE. By contrast, the $R^{2}$

350 for the modified VPM increased by $2.33 \%$, with a reduction of RMSE by $8.16 \%$

351 (Table 3). These suggested that the minimum method was more robust in quantifying

352 environmental effects on GPP than the multiplication method, which agreed well with

353 the classical ecological theory of the Liebig's law of minimum (Liebig, 1842). Yuan et

354 al. (2007) also indicated that the actual LUE was predominated by moisture

355 conditions throughout the growing season, and by temperature only at the beginning

356 and end of the growing season.

The underestimation of GPP by the VPM as mentioned in section 3.1 (Table 2),

may be partly due to the multiplication method to integrate the environmental stresses.

359 Since both the values of $f t$ and $f w$ ranged from 0 to 1 , the value of $f t \times f w$ should be

360 smaller than either $f t$ or $f w$, therefore may overestimate the environmental stress on

361 LUE and thus underestimate ecosystem GPP. For example, the underestimation of

362 VPM would be greatly reduced (the BIAS decreased from $-1.33 \mathrm{~g} \mathrm{C} \mathrm{m}^{-2}$ day $^{-1}$ to -0.94

$363 \mathrm{~g} \mathrm{C} \mathrm{m}^{-2} \mathrm{day}^{-1}$ ) when we accounted for the environmental stresses following the

364 minimum method (Table 3).

\subsection{Comparisons of the methods to define water stress}



condition (i.e., $\mathrm{VPD}_{\mathrm{s}}$ ) and/or soil water content (i.e., $W_{\mathrm{s}}$ ), or via land water index (i.e.,

WI) that can reflect the vegetation water stress in different LUE models, yet there were controversies on which one was optimal (Medlyn, et al., 2011; Hashimoto et al., accuracies might be improved by adding $\mathrm{VPD}_{\mathrm{s}}$, we thus tried to add three types of $\mathrm{VPD}_{\mathrm{s}}$, including the $\mathrm{VPD}_{\mathrm{s}}$ of GLO-PEM (Eq. (2.2d)), MODIS-GPP (Eq. (2.5)), and SWH (Eq. (2.6)), to these two models to test whether the modeling accuracy can be further enhanced. Results indicated that the improvement for EC-LUE was minor

377 despite how we defined water stress (i.e., $\min \left(W I, V P D_{s}\right)$, or $W I \times V P D_{s}$, or $V P D_{s}$ ) and

378 integrated multiple environmental stresses (multiplication or minimum). More

379 specifically, the mean $R^{2}$ elevated only if we defined the water stress as $\min (W I$, $V P D_{s}$ ), addressed multiple environmental stresses $(f)$ by minimum method (i.e., $\left.f=\min \left(f t, W I, V P D_{s}\right)\right)$, and used the $\mathrm{VPD}_{\mathrm{s}}$ from the GLO-PEM and $\mathrm{SWH}$ (increased by $1.45 \%$, Fig.3a).

In contrast, the accuracy of VPM improved substantially when we added $\mathrm{VPD}_{\mathrm{s}}$, no matter how we defined the water stress, and how we integrated the water and temperature stress into $f$ (Figs.3b-3g). The modeling accuracy reached to a maximum when $f$ was defined as $\min \left(f t, W I \times V P D_{s}\right)$ and the $\mathrm{VPD}_{\mathrm{s}}$ was from GLO-PEM or SWH.

387 The overall $R^{2}$ (i.e., 0.74 ) increased by $8.82 \%$, accompanying by a decrease of RMSE 
changes in cropland and DBF, and evident improvements in the other vegetation types (i.e., the $R^{2}$ increases ranged from $5.28 \%$ for MF to $19.69 \%$ for grassland) (Fig. $3 \mathrm{f}$ ). Notably, the model performances of VPM can be improved even if we defined the water stress by $\mathrm{VPD}_{\mathrm{s}}$ only, which implies that $\mathrm{VPD}_{\mathrm{s}}$ was more important than WI in VPM. For example, the overall $R^{2}$ (i.e., $0.72,0.71$ ) enhanced by $5.88 \%$ and $4.41 \%$, respectively, when we defined $f$ as $f t \times V P D_{s}$ and $\min \left(f t, V P D_{s}\right)$ with the $\mathrm{VPD}_{\mathrm{s}}$ from SWH (Figs.3d and 3g).

The weak improvement of EC-LUE and the significant improvement of VPM after adding $\mathrm{VPD}_{\mathrm{s}}$ may be mainly due to the different $f w$ used by them originally. The $f w$ in EC-LUE was defined as the evaporative fraction (EF), which is a comprehensive indicator of ecosystem water stress at canopy level (balance between soil water availability and atmospheric demand). This indicator biophysically represents vegetation water stress using energy partitioning scheme (the more energy goes to latent heat, the less water stress for the vegetation) which already contained the effect of VPD (Yuan et al., 2007). By contrast, the $f w$ in VPM was defined as the function of LSWI, which is sensitive to leaf water content instead of canopy water content (Maki et al., 2004), and the regional GPP is limited more by the moisture condition at canopy level (Xiao et al., 2010). Moreover, the LSWI cannot reflect the atmospheric water stress because of the weak effects of atmospheric water vapor on NIR (841-875 $\mathrm{nm}$ ) and SWIR (1628-1652 nm) bands that were used to calculate LSWI (Gao et al., 1996). These two might mainly explain the significant improvement of VPM model after adding VPD information. 

WI of VPM. The modified VPM may be the best LUE model in simulating large-scale terrestrial GPP provided with high-quality remote sensing data for the calculation of 1998, since the data of VGT-S10 (10-day composite Images from the VEGETATION sensor) and MODIS surface reflectance (MOD09A1) were not available for estimating the WI of the VPM in the time (Xiao et al., 2004a, 2005b). In this case, it was more appropriate to adopt the improved VPM with water stress being defined as $\mathrm{VPD}_{\mathrm{s}}$ only.

\subsection{The optimized LUE model structure and uncertainties} as follow:

$$
\begin{aligned}
& \varepsilon_{g}=\varepsilon_{\max } \times \min (f t, f w) \\
& f w=W I \times V P D_{s}
\end{aligned}
$$

429 where $f t$ is the same as that in GLO-PEM (Eq. (2.2c)), WI is the same as that in VPM

430 (Eq. (2.3b)), and $V P D_{s}$ is the same as that in GLO-PEM (Eq. (2.2d)) or SWH (Eq.

431 (2.6)). If there were no high-quality remote sensing data for calculating $W I$, the $\varepsilon_{\mathrm{g}}$ can 
alternatively be expressed as:

$$
\begin{aligned}
& \varepsilon_{g}=\varepsilon_{\max } \times f t \times f w \\
& f w=V P D_{s}
\end{aligned}
$$

where $f t, W I$, and $V P D_{s}$ are the same as that in Eq. (3.1).

structural differences in the LUE models, and the better performance of these models might be reached through use of model-depedent parameter values (this can be seen by comparing Figures 1 and 2 with the original publications of these models). For example, at the flux site US-MMS, the $R^{2}$ for the original EC-LUE reached up to 0.82 when $T_{\text {opt }}$ and $\varepsilon_{\max }$ were set to $20.33^{\circ} \mathrm{C}$ and $2.14 \mathrm{~g} \mathrm{C} \mathrm{m}^{-2} \mathrm{MJ}^{-1} \mathrm{APAR}$, respectively

(Yuan et al., 2007). This value was $10.81 \%$ higher than the $R^{2}$ (i.e., 0.74 ) of the EC-LUE in this study (with $T_{\text {opt }}$ of $25^{\circ} \mathrm{C}$ and $\varepsilon_{\max }$ of $2.25 \mathrm{~g} \mathrm{C} \mathrm{m}^{-2} \mathrm{MJ}^{-1}$ APAR). Further studies are needed to address the parameter optimization for LUE models.

\section{Conclusions}

This study provides a comprehensive assessment on the four mostly used LUE models (i.e., CASA, GLO-PEM, VPM, and EC-LUE) in estimating ecosystem GPP, using eddy covariance (EC) flux data from 51 towers that cover a wide climate range and diverse vegetation types. Results showed that the EC-LUE, GLO-PEM, and VPM had the similar accuracies and were overall more robust in modeling GPP over large areas than the CASA. Considering the complexity of model structure, however, the EC-LUE and VPM were the two optimal LUE models. Then we explored the possible 
453 further improvements of the two models by model structural optimization. Results

454 indicated that the minimum approach based on Liebig's law was better than the

455 multiplication method in addressing the multiple environmental stresses, and the

456 water stress can be better reflected by the combination use of the original water stress

457 scalar from VPM (WI) and the atmosphere water vapor deficit scalar $\left(\mathrm{VPD}_{\mathrm{s}}\right)$. The

458 accuracy of the VPM model could be enhanced even though we replaced the WI by

$459 \mathrm{VPD}_{\mathrm{s}}$ only. These suggested that the VPM model modified by using minimum method

460 and adding $\mathrm{VPD}_{\mathrm{s}}$ information was the best model in estimating terrestrial GPP over

461 large areas, and that by replacing WI with $\mathrm{VPD}_{\mathrm{s}}$ is optimal if there were no

462 high-quality remote sensing data for the calculation of WI.

463 
464 This work is financially supported by the National Science and Technology Support

465 Project (2013BAC03B04), the Natural Sciences Foundation of China (41301043, 466 40971027), the foundation for young scholars of IGSNRR (2013RC203), Chinese

467 Academy of Sciences project (KZCX2-XB3-08-01), and the Startup Foundation for 468 Introducing Talent of NUIST (S8113115001). We thank all site investigators, their

469 funding agencies, the various regional flux networks (Afriflux, AmeriFlux, AsiaFlux,

470 CarboAfrica, CarboEurope-IP, ChinaFlux, Fluxnet-Canada, KoFlux, LBA, NECC,

471 OzFlux, TCOS-Siberia, USCCC), the Office of Science (BER) and US Department of

472 Energy (for funding the development of measurement and data submission protocols),

473 and the Fluxnet project, whose work and support is essential for obtaining the

474 measurements without which the analyses conducted in this study would not be

475 possible. We thank two anonymous reviewers for their valuable comments to improve 476 this manuscript. 


\section{References}

Barr, A.G., Black, T.A., Hogg, E.H., Griffis, T.J., Morgenstern, K., Kijun, N., Theede, A., Nesic, Z., 2007. Climatic controls on the carbon and water balances of a boreal aspen forest, 1994-2003. Global Change Biol. 13, 561-576.

Boles, S.H., Xiao, X., Liu, J., Zhang, Q., Munkhtuya, S., Chen, S., Ojima, D., 2004. Land cover characterization of Temperate East Asia using multi-temporal VEGETATION sensor data. Remote Sens. Environ. 90, 477-489.

Bonan, G.B., Lawrence, P.J., Oleson, K.W., Levis, S., Jung, M., Reichstein, M., Lawrence, D.M., Swenson, S.C., 2011. Improving canopy processes in the Community Land Model version 4 (CLM4) using global flux fields empirically inferred from FLUXNET data. J. Geophys. Res. 116, G02014.

Bond $\square$ Lamberty, B., Wang, C., Gower, S.T., 2004. Net primary production and net ecosystem production of a boreal black spruce wildfire chronosequence. Glob. Change Biol. 10, 473-487.

Canadell, J., Mooney, H., Baldocchi, D., Berry, J., Ehleringer, J., Field, C., Gower, S., Hollinger, D., Hunt, J., Jackson, R.B., 2000. Commentary: Carbon metabolism of the terrestrial biosphere: A multitechnique approach for improved understanding. Ecosystems 3, 115-130.

Cao, M., Prince, S.D., Small, J., Goetz, S.J., 2004. Remotely sensed interannual variations and trends in terrestrial net primary productivity 1981-2000. Ecosystems 7, 233-242.

Chapin III, F.S., Matson, P.P.A., 2002. Principles of terrestrial ecosystem ecology. Springer, New York.

Colin Prentice, I., Sykes, M.T., Cramer, W., 1993. A simulation model for the transient effects of climate change on forest landscapes. Ecol. Model. 65, 51-70.

Cook, B.D., Bolstad, P.V., Martin, J.G., Heinsch, F.A., Davis, K.J., Wang, W., Desai, A.R., Teclaw, 

carbon exchange during forest canopy disturbance. Ecosystems 11, 26-44.

501 Coops, N.C., Ferster, C.J., Waring, R.H., Nightingale, J., 2009. Comparison of three models for predicting gross primary production across and within forested ecoregions in the contiguous United States. Remote Sens. Environ. 113, 680-690.

Coursolle, C., Margolis, H.A., Barr, A.G., Black, T.A., Amiro, B.D., McCaughey, J.H., Flanagan, L.B., Lafleur, P.M., Roulet, N.T., Bourque, C.P.-A., Arain, M.A., Wofsy, S.C., Dunn, A., Morgenstern, transect. Canadian Journal of Forest Research 36, 783-800.

Curtis, P.S., Hanson, P.J., Bolstad, P., Barford, C., Randolph, J., Schmid, H., Wilson, K.B., 2002. Biometric and eddy-covariance based estimates of annual carbon storage in five eastern North American deciduous forests. Agric. For. Meteorol. 113, 3-19.

Desai, A.R., Bolstad, P.V., Cook, B.D., Davis, K.J., Carey, E.V., 2005. Comparing net ecosystem exchange of carbon dioxide between an old-growth and mature forest in the upper Midwest, USA. Agric. For. Meteorol. 128, 33-55.

Dragoni, D., Schmid, H., Grimmond, C., Loescher, H., 2007. Uncertainty of annual net ecosystem productivity estimated using eddy covariance flux measurements. J. Geophys. Res. 112, D17102. 2005. A MODIS-derived photochemical reflectance index to detect inter-annual variations in the 
Drolet, G.G., Middleton, E.M., Huemmrich, K.F., Hall, F.G., Amiro, B.D., Barr, A.G., Black, T.A., McCaughey, J.H., Margolis, H.A., 2008. Regional mapping of gross light-use efficiency using MODIS spectral indices. Remote Sens. Environ. 112, 3064-3078.

Field, C.B., Randerson, J.T., Malmström, C.M., 1995. Global net primary production: combining ecology and remote sensing. Remote Sens. Environ. 51, 74-88.

Gamon, J., Coburn, C., Flanagan, L., Huemmrich, K., Kiddle, C., Sanchez-Azofeifa, G., Thayer, D., Vescovo, L., Gianelle, D., Sims, D., 2010. SpecNet revisited: bridging flux and remote sensing communities. Can. J. Remote Sens. 36, S376-S390.

Gao, B.C., 1996. NDWI-a normalized difference water index for remote sensing of vegetation liquid water from space. Remote Sens. Environ. 58, 257-266.

Gerbig, C., Lin, J., Wofsy, S., Daube, B., Andrews, A., Stephens, B., Bakwin, P., Grainger, C., 2003. Toward constraining regional-scale fluxes of $\mathrm{CO}_{2}$ with atmospheric observations over a continent: 2. Analysis of COBRA data using a receptor-oriented framework. J. Geophys. Res. 108, 4757.

Gilmanov, T.G., Aires, L., Barcza, Z., Baron, V., Belelli, L., Beringer, J., Billesbach, D., Bonal, D., Bradford, J., Ceschia, E., 2010. Productivity, respiration, and light-response parameters of world grassland and agroecosystems derived from flux-tower measurements. Rangeland ecol. Manag. 63, 16-39.

Gioli, B., Miglietta, F., De Martino, B., Hutjes, R.W., Dolman, H.A., Lindroth, A., Schumacher, M., Sanz, M.J., Manca, G., Peressotti, A., 2004. Comparison between tower and aircraft-based eddy covariance fluxes in five European regions. Agric. For. Meteorol. 127, 1-16.

Gitelson, A.A., Viña, A., Arkebauer, T.J., Rundquist, D.C., Keydan, G., Leavitt, B., 2003. Remote estimation of leaf area index and green leaf biomass in maize canopies. Geophys. Res. Lett. 30, 
544 Goetz, S.J., Prince, S.D., Goward, S.N., Thawley, M.M., Small, J., 1999. Satellite remote sensing of

545 primary production: an improved production efficiency modeling approach. Ecol. Model. 122, $239-255$

Goldstein, A., Hultman, N., Fracheboud, J., Bauer, M., Panek, J., Xu, M., Qi, Y., Guenther, A., Baugh, W., 2000. Effects of climate variability on the carbon dioxide, water, and sensible heat fluxes above a ponderosa pine plantation in the Sierra Nevada (CA). Agric. For. Meteorol. 101, 113-129.

Goulden, M.L., McMillan, A., Winston, G., Rocha, A., Manies, K., Harden, J.W., Bond $\square$ Lamberty, B., 2011. Patterns of NPP, GPP, respiration, and NEP during boreal forest succession. Glob. Change Biol. 17, 855-871.

Groenendijk, M., Van Der Molen, M.K., Dolman, A.J., 2009. Seasonal variation in ecosystem parameters derived from FLUXNET data. Biogeosciences Discussions 6, 2863-2912.

Guerschman, J.P., Van Dijk, A.I., Mattersdorf, G., Beringer, J., Hutley, L.B., Leuning, R., Pipunic, R.C., Sherman, B.S., 2009. Scaling of potential evapotranspiration with MODIS data reproduces flux observations and catchment water balance observations across Australia. J. Hydrol. 369, 107-119. ecosystem $\mathrm{CO}_{2}$ flux measurements for estimation of canopy PAR absorption. Glob. Change Biol. $8,563-574$.

Hashimoto, H., Wang, W., Milesi, C., Xiong, J., Ganguly, S., Zhu, Z., Nemani, R.R., 2013. Structural Uncertainty in Model-Simulated Trends of Global Gross Primary Production. Remote Sensing 5, $1258-1273$.

Heinsch, F.A., Reeves, M., Votava, P., Kang, S., Milesi, C., Zhao, M., Glassy, J., Jolly, W.M., Loehman, 
Hickler, T., Prentice, I.C., Smith, B., Sykes, M.T., Zaehle, S., 2006. Implementing plant hydraulic architecture within the LPJ Dynamic Global Vegetation Model. Glob. Ecol. Biogeogr. 15, $567-577$.

Hill, M.J., Senarath, U., Lee, A., Zeppel, M., Nightingale, J.M., Williams, R.D.J., McVicar, T.R., 2006. Assessment of the MODIS LAI product for Australian ecosystems. Remote Sens. Environ. 101,

Hollinger, D., Aber, J., Dail, B., Davidson, E., Goltz, S., Hughes, H., Leclerc, M., Lee, J., Richardson, A., Rodrigues, C., 2004. Spatial and temporal variability in forest-atmosphere $\mathrm{CO}_{2}$ exchange.

Hollinger, S.E., Bernacchi, C.J., Meyers, T.P., 2005. Carbon budget of mature no-till ecosystem in North Central Region of the United States. Agric. For. Meteorol. 130, 59-69.

Hu, Z., Li, S., Yu, G., Sun, X., Zhang, L., Han, S., Li, Y., 2013. Modeling evapotranspiration by combing a two-source model, a leaf stomatal model, and a light-use efficiency model. J. Hydrol.

Jamali, H., Livesley, S.J., Dawes, T.Z., Cook, G.D., Hutley, L.B., Arndt, S.K., 2011. Diurnal and seasonal variations in $\mathrm{CH}_{4}$ flux from termite mounds in tropical savannas of the Northern Territory, Australia. Agric. For. Meteorol. 151, 1471-1479. found in canopies in the field. Philos. Trans. R. Soc. Lond. B 273, 593-610. 
Jönsson, P., Eklundh, L., 2004. TIMESAT—A program for analyzing time-series of satellite sensor data. Comput. Geosci. 30, 833-845.

590

591

592

593

594

595

596

Kalfas, J.L., Xiao, X., Vanegas, D.X., Verma, S.B., Suyker, A.E., 2011. Modeling gross primary production of irrigated and rain-fed maize using MODIS imagery and $\mathrm{CO}_{2}$ flux tower data. Agric. For. Meteorol. 151, 1514-1528.

Kotchenova, S.Y., Song, X., Shabanov, N.V., Potter, C.S., Knyazikhin, Y., Myneni, R. B., 2004. Lidar remote sensing for modeling gross primary production of deciduous forests. Remote Sens. Environ. 92, 158-172.

Kramer, K., Leinonen, I., Bartelink, H., Berbigier, P., Borghetti, M., Bernhofer, C., Cienciala, E., Dolman, A., Froer, O., Gracia, C., 2002. Evaluation of six process $\square$ based forest growth models using eddy $\square$ covariance measurements of $\mathrm{CO}_{2}$ and $\mathrm{H}_{2} \mathrm{O}$ fluxes at six forest sites in Europe. Glob. Change Biol. 8, 213-230.

Kurc, S.A., Small, E.E., 2004. Dynamics of evapotranspiration in semiarid grassland and shrubland ecosystems during the summer monsoon season, central New Mexico. Water Resources Research 40, W09305.

Landsberg, J.J., 1986. Physiological ecology of forest production. Academic Press, London, 165-178.

Law, B., Anthoni, P., Aber, J., 2000. Measurements of gross and net ecosystem productivity and water vapour exchange of a Pinus ponderosa ecosystem, and an evaluation of two generalized models. Glob. Change Biol. 6, 155-168.

Liebig, J., 1842. Chemistry in its Application to Agriculture and Physiology. Cambridge, J. Owen.

Liu, J., Sun, O.J., Jin, H., Zhou, Z., Han, X., 2011. Application of two remote sensing GPP algorithms 
Maki, M., Ishiahra, M., Tamura, M., 2004. Estimation of leaf water status to monitor the risk of forest fires by using remotely sensed data. Remote Sens. Environ. 90, 441-450. Taskinen, M.R., 1997. Defective regulation of triglyceride metabolism by insulin in the liver in NIDDM. Diabetologia 40, 454-462. Production from 2000 Through 2009". Science 333, 1093. Dioxide Inf. Anal. Cent., Oak Ridge Natl. Lab., Oak Ridge, Tenn. gov/pub/ameriflux/data/Level4/Sites-Byname/Fort-Peck/. Carbon Dioxide Inf. Anal. Cent., Oak Ridge Natl. Lab., Oak Ridge, Tenn.

Mu, Q., Heinsch, F.A., Zhao, M., Running, S.W., 2007. Development of a global evapotranspiration algorithm based on MODIS and global meteorology data. Remote Sens. Environ. 111, 519-536. 

throughfall exclusion on canopy processes, aboveground production, and biogeochemistry of an Amazon forest. J. Geophys. Res. 107, D20.

Oak Ridge National Laboratory Distributed Active Archive Center (ORNL DAAC)., 2012. FLUXNET Web Page. Available online [http://Fluxnet.ornl.gov] from ORNL DAAC, Oak Ridge, Tennessee, U.S.A. Accessed November 5, 2012.

Papale, D., Valentini, R., 2003. A new assessment of European forests carbon exchanges by eddy fluxes and artificial neural network spatialization. Glob. Change Biol. 9, 525-535.

Potter, C.S., Randerson, J.T., Field, C.B., Matson, P.A., Vitousek, P.M., Mooney, H.A., Klooster, S.A., 1993. Terrestrial ecosystem production: a process model based on global satellite and surface data. Global Biogeochem. Cy. 7, 811-841.

Prentice, I.C., Cramer, W., Harrison, S.P., Leemans, R., Monserud, R.A., Solomon, A.M., 1992. Special paper: a global biome model based on plant physiology and dominance, soil properties and climate. J. Biogeogr. 117-134.

Priestley, C., Taylor, R., 1972. On the assessment of surface heat flux and evaporation using large-scale parameters. Mon. weather rev. 100, 81-92.

Prince, S.D., Goward, S.N., 1995. Global primary production: a remote sensing approach. J. Biogeogr. $815-835$

Reichstein, M., Falge, E., Baldocchi, D., Papale, D., Aubinet, M., Berbigier, P., Bernhofer, C., Buchmann, N., Gilmanov, T., Granier, A., 2005. On the separation of net ecosystem exchange into assimilation and ecosystem respiration: review and improved algorithm. Glob. Change Biol. 11, 1424-1439.

Reichstein, M., Rey, A., Freibauer, A., Tenhunen, J., Valentini, R., Banza, J., Casals, P., Cheng, Y., 
Richardson, A.D., Jenkins, J.P., Braswell, B.H., Hollinger, D.Y., Ollinger, S.V., Smith, M.L., 2007. Use

Running, S.W., Nemani, R., Glassy, J.M., Thornton, P.E., 1999. MODIS daily photosynthesis (PSN) $547-560$.

Running, S.W., Thornton, P.E., Nemani, R., Glassy, J.M., 2000. Global terrestrial gross and net primary productivity from the Earth Observing System. In Methods in ecosystem science 44-57. Springer seasonal $\mathrm{CO}_{2}$ flux for diverse vegetation types and climate conditions. Biogeosciences 6, 585-599.

Sala, O.E., Parton, W.J., Joyce, L.A., Lauenroth, W.K., 1988. Primary production of the central grassland region of the United States. Ecology, 69, 40-45. characteristics from texture. Soil Sci. Soc. Am. J. 50, 1031-1036.

674 Smith, P., Lanigan, G., Kutsch, W.L., Buchmann, N., Eugster, W., Aubinet, M., Ceschia, E., Béziat, P., 

carbon budget of croplands. Agr. Ecosyst. Environ. 139, 302-315.

677 Van Huissteden, J., Maximov, T., Dolman, A., 2005. High methane flux from an arctic floodplain (Indigirka lowlands, eastern Siberia). J. Geophys. Res. 110, G02002.

Veenendaal, E.M., Kolle, O., Lloyd, J., 2004. Seasonal variation in energy fluxes and carbon dioxide exchange for a broad-leaved semi-arid savanna (Mopane woodland) in Southern Africa. Glob. Change Biol. 10, 318-328. Burba, G.G., Amos, B., Yang, H., 2005. Annual carbon dioxide exchange in irrigated and rainfed maize-based agroecosystems. Agric. For. Meteorol. 131, 77-96. retrieval using thermal inertia, determined with visible and thermal spaceborne data, validated for European forests. Remote Sens. Environ. 101, 299-314.

Wilson, K.B., Baldocchi, D.D., Hanson, P.J., 2001. Leaf age affects the seasonal patterns of photosynthetic capacity and net ecosystem exchange of carbon in a deciduous forest. Plant, Cell \&

Wu, C., Munger, J.W., Niu, Z., Kuang, D., 2010. Comparison of multiple models for estimating gross Environment, 24, 571- 583. 

$114,576-591$.

Xiao, X., Boles, S., Liu, J., Zhuang, D., Liu, M., 2002. Characterization of forest types in Northeastern

Xiao, X., Hollinger, D., Aber, J., Goltz, M., Davidson, E.A., Zhang, Q., Moore III, B., 2004a. Satellite-based modeling of gross primary production in an evergreen needleleaf forest. Remote Sens. Environ. 89, 519-534. Modeling gross primary production of temperate deciduous broadleaf forest using satellite images and climate data. Remote Sens. Environ. 91, 256-270.

Xiao, X., Zhang, Q., Hollinger, D., Aber, J., Moore III, B., 2005a. Modeling gross primary production of an evergreen needleleaf forest using MODIS and climate data. Ecol. Appl. 15, 954-969.

Xiao, X., Zhang, Q., Saleska, S., Hutyra, L., De Camargo, P., Wofsy, S., Frolking, S., Boles, S., Keller, M., Moore III, B., 2005b. Satellite-based modeling of gross primary production in a seasonally moist tropical evergreen forest. Remote Sens. Environ. 94, 105-122. terrestrial ecosystems from MODIS imagery. J. Geophys. Res. 118, 590-605. 

I.A., Jung, M., Kato, T., Kiely, G., Liu, D., Marcolla, B., Montagnani, L., Raschi, A., Roupsard, O., Meteorol. 192, 108-120.

Yuan, W., Liu, S., Yu, G., Bonnefond, J.-M., Chen, J., Davis, K., Desai, A.R., Goldstein, A.H., Gianelle, D., Rossi, F., 2010. Global estimates of evapotranspiration and gross primary production based on MODIS and global meteorology data. Remote Sens. Environ. 114, 1416-1431. A.H., Goulden, M.L., 2007. Deriving a light use efficiency model from eddy covariance flux data for predicting daily gross primary production across biomes. Agric. For. Meteorol. 143, 189-207. 
733 Table 1. Descriptions of the eddy covariance (EC) flux sites in this study including vegetation

734 type (Veg-Type), site identifier (Site ID), latitude (Lat), longitude (Lon), data period, country, and

735 references.

\begin{tabular}{|c|c|c|c|c|c|c|}
\hline Veg-Type & Site ID & Lat $\left({ }^{\circ} \mathrm{N}\right)$ & $\operatorname{Lon}\left({ }^{\circ} \mathrm{E}\right)$ & Data period & Country & References \\
\hline Savanna & AU-Fog & -12.542 & 131.307 & 2006-2007 & Australia & Guerschman et al. (2009) \\
\hline Savanna & AU-How & -12.494 & 131.152 & $2001-2006$ & Australia & Jamali et al. (2010) \\
\hline Savanna & BW-Ma1 & -19.916 & 23.560 & $2000-2001$ & Botswana & Veenendaal et al. (2004) \\
\hline Savanna & US-Ton & 38.432 & -120.966 & $2001-2006$ & USA & Yuan et al. (2007) \\
\hline Grassland & IT-Amp & 41.904 & 13.605 & $2002-2006$ & Italy & Gilmanov et al. (2007) \\
\hline Grassland & NL-Ca1 & 51.971 & 4.927 & 2003-2006 & Netherlands & Gioli et al. (2004) \\
\hline Grassland & NL-Hor & 52.029 & 5.068 & $2005-2006$ & Netherlands & Smith et al. (2010) \\
\hline Grassland & US-Aud & 31.591 & -110.510 & $2002-2006$ & USA & Meyers (2009a) \\
\hline Grassland & US-Fpe & 48.308 & -105.102 & $2000-2006$ & USA & Meyers (2009b) \\
\hline Grassland & US-Goo & 34.255 & -89.873 & $2002-2006$ & USA & Yuan et al. (2007) \\
\hline Grassland & US-Var & 38.413 & -120.951 & 2001-2006 & USA & Mu et al. (2007) \\
\hline Cropland & NL-Lan & 51.954 & 4.903 & $2005-2006$ & Netherlands & Moors et al. (2010) \\
\hline Cropland & US-ARM & 36.606 & -97.489 & 2003-2006 & USA & Hanan et al. (2002) \\
\hline Cropland & US-Bkg & 38.895 & -120.633 & 2004-2006 & USA & Goldstein et al. (2000) \\
\hline Cropland & US-Bo1 & 44.345 & -96.836 & $2000-2007$ & USA & Hollinger et al. (2005) \\
\hline Cropland & US-Ne1 & 41.165 & -96.477 & $2001-2005$ & USA & Verma et al. (2005) \\
\hline Cropland & US-Ne2 & 41.165 & -96.470 & $2001-2005$ & USA & Verma et al. (2005) \\
\hline Cropland & US-Ne3 & 41.180 & -96.440 & 2001-2005 & USA & Gitelson et al. (2003) \\
\hline Shrubland & CA-NS7 & 56.636 & -99.948 & $2002-2005$ & Canada & Goulden et al. (2011) \\
\hline Shrubland & RU-Cok & 70.617 & 147.883 & 2003-2005 & Russia & vanHuissteden. 2005 \\
\hline MF & CA-SF2 & 54.254 & -105.878 & 2003-2005 & Canada & Coursolle et al. (2006) \\
\hline MF & US-Ho1 & 45.204 & -68.740 & $2000-2004$ & USA & Hollinger et al. (2004) \\
\hline $\mathrm{MF}$ & US-Pfa & 45.946 & -90.272 & 2000,2003 & USA & Gerbig (2003) \\
\hline MF & US-Syv & 46.242 & -89.348 & $2002-2006$ & USA & Desai et al. (2005) \\
\hline DBF & IT-Ro1 & 42.408 & 11.930 & $2000-2006$ & Italy & Reichstein (2003) \\
\hline DBF & IT-Ro2 & 42.390 & 11.921 & $2002-2006$ & Italy & Reichstein (2003) \\
\hline DBF & US-Bar & 44.065 & -71.288 & 2004-2005 & USA & Saito et al. (2009) \\
\hline DBF & US-Ha1 & 42.538 & -72.172 & $2000-2006$ & USA & Saito et al. (2009) \\
\hline DBF & US-MMS & 39.323 & -86.413 & $2000-2005$ & USA & Dragoni et al. (2007) \\
\hline DBF & US-UMB & 45.560 & -84.714 & $2000-2003$ & USA & Curtis et al. (2002) \\
\hline DBF & US-WCr & 45.806 & -90.080 & $2000-2006$ & USA & Cook et al. (2008) \\
\hline $\mathrm{EBF}$ & AU-Tum & -35.656 & 148.152 & $2001-2006$ & Australia & Guerschman et al. (2009) \\
\hline $\mathrm{EBF}$ & IT-Cpz & 41.705 & 12.376 & $2000-2006$ & Italy & Hickler et al. (2006) \\
\hline ENF & CA-Man & 55.880 & -98.481 & $2000-2003$ & Canada & Groenendijk et al. (2009) \\
\hline ENF & CA-NS1 & 55.879 & -98.484 & $2002-2005$ & Canada & Goulden et al. (2011) \\
\hline ENF & CA-NS2 & 55.906 & -98.525 & $2001-2005$ & Canada & Goulden et al. (2011) \\
\hline ENF & CA-NS3 & 55.912 & -98.382 & $2001-2005$ & Canada & Goulden et al. (2011) \\
\hline
\end{tabular}




\begin{tabular}{lllllll} 
ENF & CA-NS4 & 55.912 & -98.382 & $2002-2004$ & Canada & Bond-Lamberty et al. (2004) \\
ENF & CA-NS5 & 55.863 & -98.485 & $2001-2005$ & Canada & Bond-Lamberty et al. (2004) \\
ENF & CA-NS6 & 55.917 & -98.964 & $2001-2005$ & Canada & Bond-Lamberty et al. (2004) \\
ENF & CA-Qcu & 49.267 & -74.036 & $2001-2006$ & Canada & Coursolle et al. (2006) \\
ENF & CA-Qfo & 49.693 & -74.342 & $2003-2006$ & Canada & Bonan et al. (2011) \\
ENF & CA-SF1 & 54.485 & -105.818 & $2003-2005$ & Canada & Coursolle et al. (2006) \\
ENF & CA-SF3 & 54.092 & -106.005 & $2003-2005$ & Canada & Coursolle et al. (2006) \\
ENF & DE-Tha & 50.964 & 13.567 & $2000-2006$ & Germany & Kramer et al. (2002) \\
ENF & FI-Hyy & 61.847 & 24.295 & $2000-2006$ & Finland & Kramer et al. (2002) \\
ENF & IL-Yat & 31.345 & 35.051 & $2001-2006$ & Israel & Reichstein et al. (2005) \\
ENF & SE-Faj & 64.113 & 19.457 & $2005-2006$ & Sweden & Gamon et al. (2010) \\
ENF & SE-Fla & 60.086 & 17.480 & $2000-2002$ & Sweden & Verstraeten et al. (2006) \\
ENF & US-Blo & 40.006 & -88.290 & $2000-2006$ & USA & Goldstein et al. (2000) \\
ENF & US-Me4 & 44.499 & -121.622 & $2000-2000$ & USA & Law et al. (2000) \\
\hline
\end{tabular}


736 Table 2. Accuracies of EC-LUE, VPM, GLO-PEM, and CASA in estimating GPP across the eight

737 vegetation types as reflected by $R^{2}$, RMSE, and BIAS.

\begin{tabular}{cccccccccccccc}
\hline \multirow{2}{*}{$\begin{array}{c}\text { Vegetation } \\
\text { Type }\end{array}$} & \multicolumn{4}{c}{$R^{2}$} & \multicolumn{4}{c}{ RMSE $\left(\mathrm{g} \mathrm{C} \mathrm{m}^{-2}\right.$ day $\left.^{-1}\right)$} & \multicolumn{4}{c}{${\text { BIAS }\left(\mathrm{g} \mathrm{C} \mathrm{m}^{-2} \mathrm{day}^{-1}\right)}$} \\
\cline { 2 - 12 } & EC-LUE & VPM & GLO-PEM & CASA & EC-LUE & VPM & GLO-PEM & CASA & EC-LUE & VPM & GLO-PEM & CASA \\
\hline Savanna & 0.66 & 0.59 & 0.63 & 0.40 & 1.77 & 1.37 & 1.50 & 3.16 & -0.17 & -0.41 & 0.62 & 2.50 \\
Grassland & 0.64 & 0.57 & 0.58 & 0.45 & 1.96 & 2.36 & 1.91 & 2.61 & -0.94 & -1.47 & -0.24 & -0.02 \\
Cropland & 0.73 & 0.70 & 0.67 & 0.59 & 2.95 & 4.65 & 3.77 & 3.51 & -1.29 & -2.88 & -1.17 & -0.38 \\
Shrubland & 0.63 & 0.65 & 0.60 & 0.51 & 1.27 & 1.41 & 1.07 & 1.60 & -0.85 & -1.07 & 0.18 & -0.14 \\
MF & 0.74 & 0.78 & 0.80 & 0.72 & 3.36 & 3.21 & 2.29 & 2.54 & -2.78 & -2.65 & -1.76 & -1.95 \\
DBF & 0.76 & 0.82 & 0.76 & 0.76 & 2.88 & 2.50 & 2.13 & 2.32 & -1.83 & -1.46 & -0.50 & -0.27 \\
EBF & 0.51 & 0.58 & 0.61 & 0.50 & 4.02 & 3.56 & 2.77 & 3.27 & -3.80 & -1.41 & -2.27 & -2.26 \\
ENF & 0.69 & 0.68 & 0.71 & 0.60 & 2.08 & 1.67 & 1.52 & 1.82 & -1.71 & -0.56 & -0.80 & -0.81 \\
\hline Average & 0.69 & 0.68 & 0.69 & 0.58 & 2.41 & 2.45 & 2.06 & 2.44 & -1.57 & -1.33 & -0.72 & -0.43 \\
\hline
\end{tabular}

738

739 
739 Table 3. Comparisons of modeling accuracies (as reflected by $R^{2}$, RMSE, and BIAS) of the

740 EC-LUE and VPM when we assumed the environmental impacts as multiplication with that as

741 minimum based on Liebig's law.

\begin{tabular}{|c|c|c|c|c|c|c|}
\hline & \multicolumn{3}{|c|}{$f t \times f w$} & \multicolumn{3}{|c|}{$\min (f t, f w)$} \\
\hline & $R^{2}$ & $\operatorname{RMSE}\left(\mathrm{g} \mathrm{C} \mathrm{m}^{-2}\right.$ day $\left.^{-1}\right)$ & BIAS(g C m ${ }^{-2}$ day $\left.^{-1}\right)$ & $R^{2}$ & $\operatorname{RMSE}\left(\mathrm{g} \mathrm{C} \mathrm{m}^{-2} \mathrm{day}^{-1}\right)$ & $\operatorname{BIAS}\left(\mathrm{g} \mathrm{C} \mathrm{m}^{-2}\right.$ day $\left.^{-1}\right)$ \\
\hline EC-LUE & 0.66 & 2.68 & -1.94 & 0.69 & 2.41 & -1.57 \\
\hline VPM & 0.68 & 2.45 & -1.33 & 0.69 & 2.25 & -0.94 \\
\hline
\end{tabular}

742

743 


\section{Figure legends}

744 Figure 1. Comparisons between the observed GPP and the simulated GPP by the EC-LUE, VPM,

745 GLO-PEM, and CASA models in non-forest sites. Dashed line is the 1:1 line and solid line

746 indicates the best linear fit curve.

747 Figure 2. Comparisons between the observed GPP and the simulated GPP by the EC-LUE, VPM,

748 GLO-PEM, and CASA models in forest sites. Dashed line is the 1:1 line and solid line indicates

749 the best linear fit curve.

750 Figure 3. $R^{2}$ changes for all the vegetation types of EC-LUE (panel a) and VPM (panels b-g) after 751 adding the $\mathrm{VPD}_{\mathrm{s}}$. 

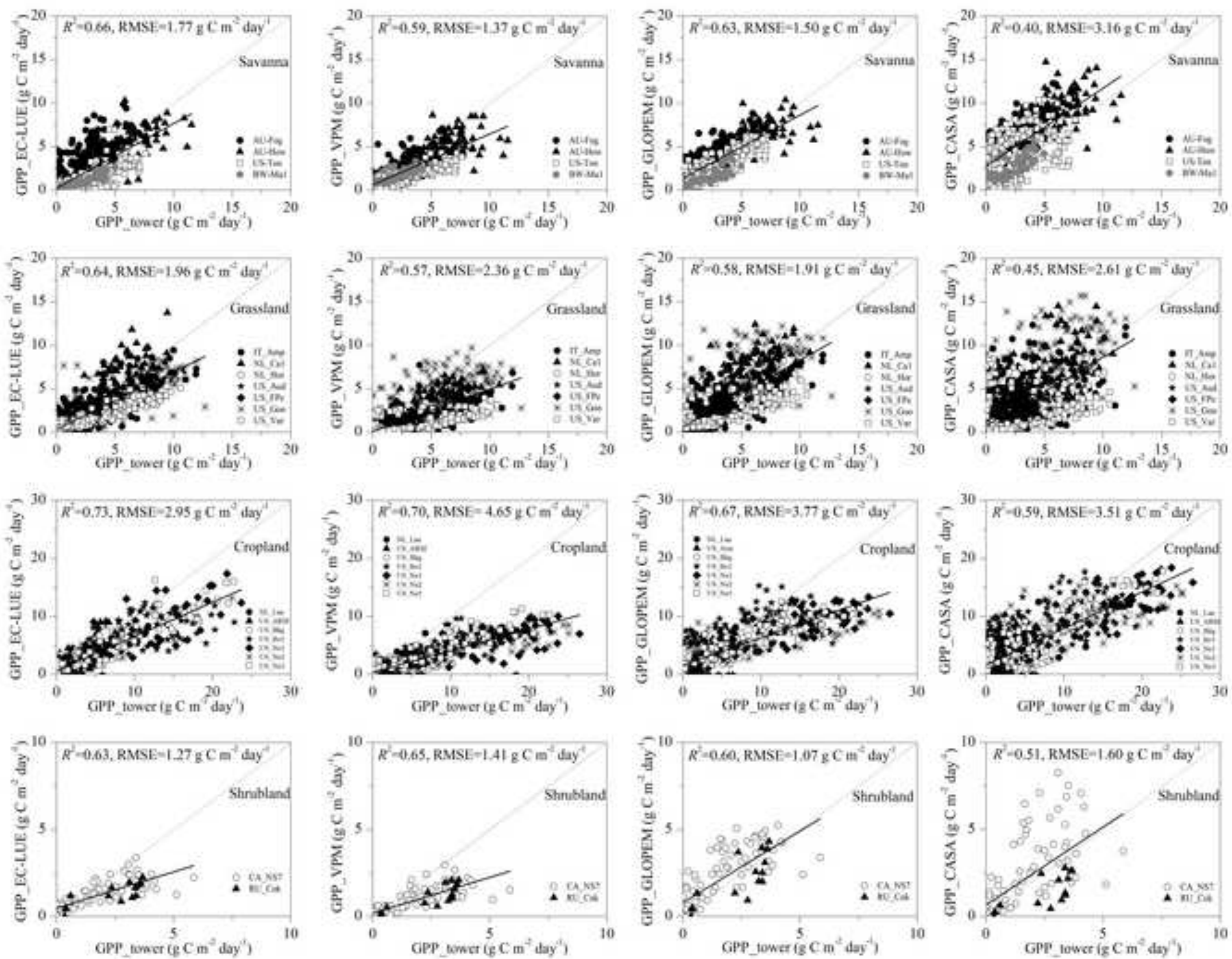

rage 44 or 46

\section{rage 44 or 46}



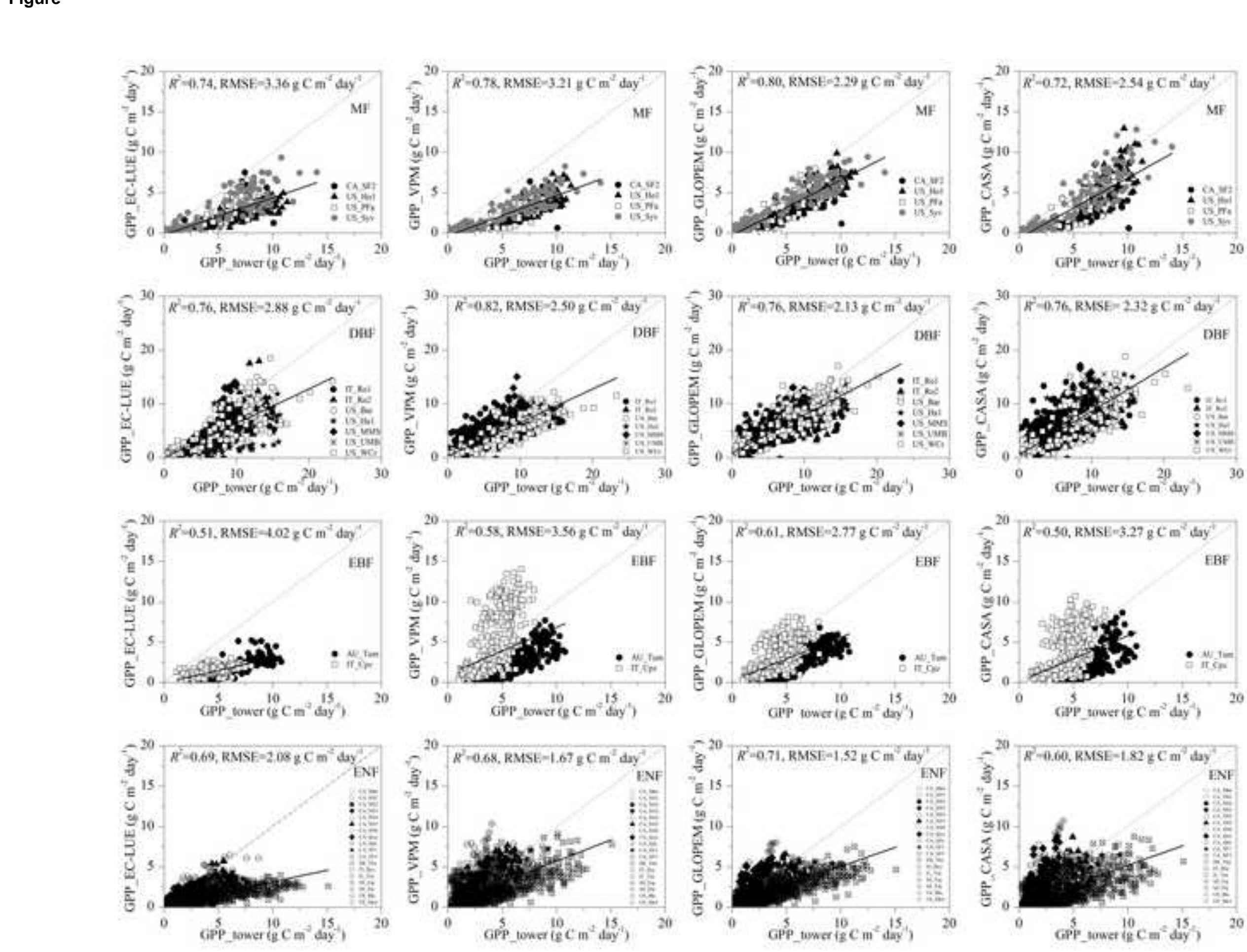

rage 45 or 46

rage 45 or 46 


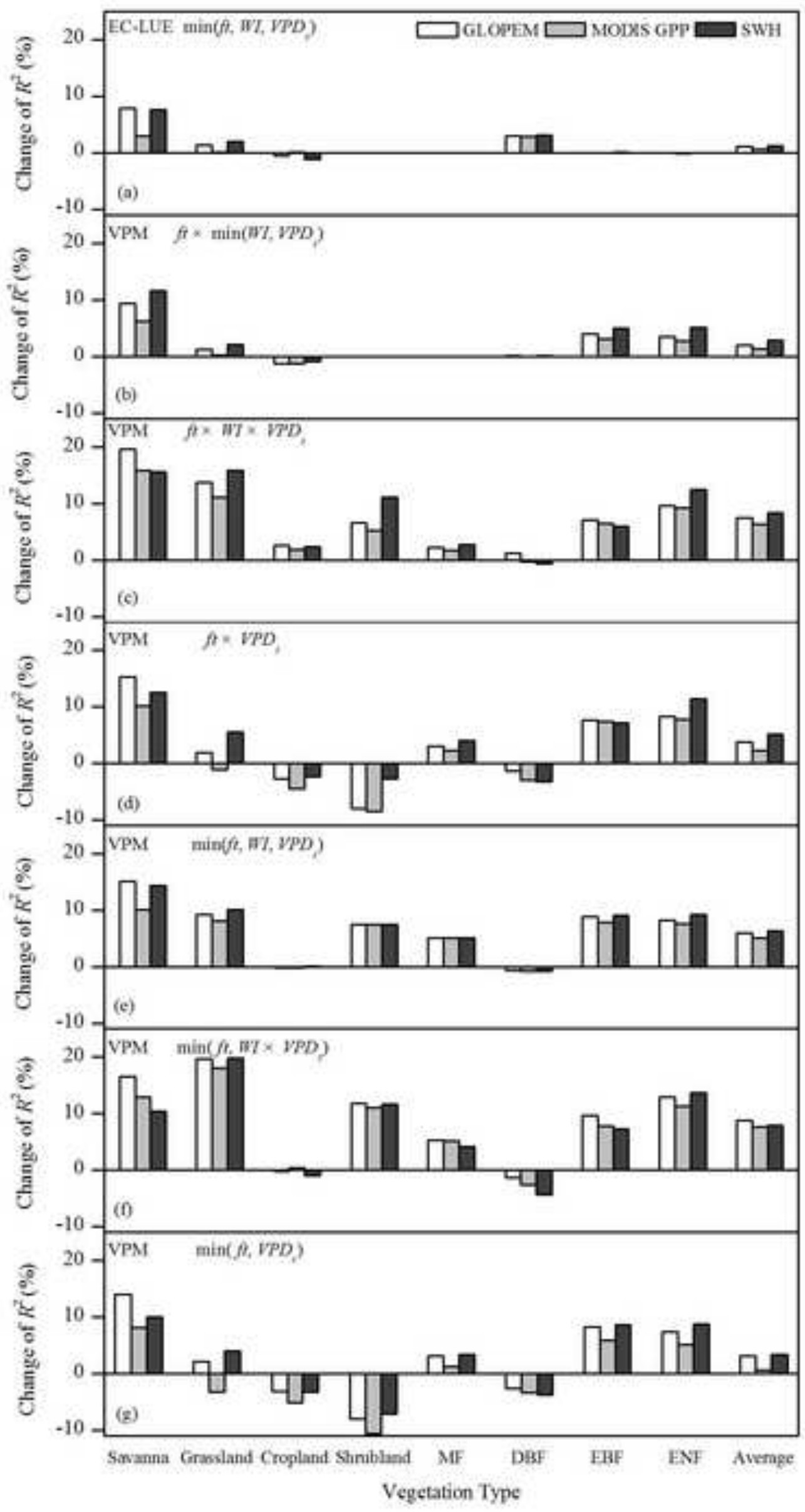

